Journal of Advanced Research in Fluid Mechanics and Thermal Sciences

Journal homepage: www.akademiabaru.com/arfmts.html ISSN: 2289-7879

\title{
Development and Evaluation of Stove Using Peltier Effect: Connection and Temperature Control
}

\author{
Arman Hadi Azaharr, ${ }^{1, *}$, Ramizah Amira Mohamad ${ }^{1}$, Mohamad Haniff Harun ${ }^{1}$, Amar Faiz Zainal \\ Abidin ${ }^{1}$, Mohd Badril Nor Shah ${ }^{1}$, Rozilawati Mohd.Nor ${ }^{1}$, Mohd Farriz Basar ${ }^{1}$
}

1 Department of Electrical Engineering Technology, Universiti Teknikal Malaysia Melaka, Hang Tuah Jaya, 76100 Durian Tunggal, Melaka, Malaysia

\section{ARTICLE INFO}

\section{Article history:}

Received 15 August 2019

Received in revised form 5 February 2020

Accepted 13 February 2020

Available online 23 April 2020

\section{ABSTRACT}

Conventionally, a stove had been used to cook and boil. The stove commonly used gasses and charcoals as the fuel element to contribute the heat for cooking. However, the gasses used such as Liquefied Petroleum Gas (LPG) is an extremely flammable gas that commonly contribute to fire while charcoals contribute largely of carbon after the charcoal burning process during cooking. In addition, these stoves are also difficult to control the flame. Therefore, a portable stove operating using Peltier effect is developed and focuses on the development of a portable stove that operates by using a Peltier to provide heat and evaluate the heating control by PID Controller. The stove is developed to evaluate the performance of Peltier Effect in order to replace the LP as a heating element. The minimum operating voltage for the Peltier Effect heating system is specify to be $10.1 \mathrm{~V}$, and the maximum is $12.6 \mathrm{~V}$, therefore if the supply is lower than the minimum threshold the Peltier will auto shut down. The number of Peltier module and type of Peltier module connection are varied to evaluate the heating performance and power consumption. The controller algorithm, Proportional Integral Derivative (PID) controller parameters are optimized to control the temperature of heating or cooling when the temperature is being adjusted to its set point.

Keywords:

Stove; Peltier effect; Heat; Temperature Control; PID Controller

\section{Introduction}

Nowadays, outdoor activities and outdoor recreation are the most activities people are involving. It is referring to leisure time in the outdoors, often in rural or town. Numerous movement can be done alone or in a bunch like experience hustling, hiking, cycling, camping, canoeing, crayoning, angling, climbing, horseback riding, chasing, kayaking, shake climbing, running, cruising, skiing, surfing, ATV riding, and sports [1].

\footnotetext{
* Corresponding author.

E-mail address: arman.hadi@utem.edu.my (Arman Hadi Azahar)
}

https://doi.org/10.37934/arfmts.70.1.112 
When go outdoor activities, all the equipment should be prepared well. More preparation should be considered such as food and beverage for those who take a long journey to do outdoor activities. People will plan their meals before the journey. People will bring along a stove as it is more convenient to cook. The stove should be ultralight and easy for people to carry during explorations.

A few decades ago, people would gather firewood to cook [1]. This traditional camp stove is not practical if the wood was wet caused by bad weather, people could not light up the fire. This method does not guarantee if the food is safe and clean to eat. All this thing may be harmful to people and environment because of the occurring open burning [2]. Wood burning contributes pollution to environment in the form of smoke when the wood was burned [3].

Nowadays there are many varieties of design and models of camp stove. These portable camp stove can be categorized based on the type of burner used and stove design [4]. There are many types of camping stove people always use like canister, liquid fuel, alcohol burning, solid fuel and wood burning [5]. Portable camp stove allowed people to cook anything wherever they are. But some of this portable stove is not suitable for high land which has a high pressure so it is difficult to light up the flame. Furthermore, these stoves do not work in extreme cold.

The current portable camp stoves are still not light in weight. Although these type of burner are small but the stove is still heavy to bring. People also will bring the fuel according to how long the duration. Then, people should bring many burners for long distance explorations. The heat distribution, pollution, safety, the stove weight is difference based on the characteristics.

Flame, heat and temperature are three main elements to cook food or boil drink. In term of safety, these stoves are produced heat which are also difficult to be controlled by the flame. Unfortunately, the heat and temperature produced are hardly to control manually caused of the flame is depend on the stove types and the environment effect. Stove flames are control the heat by regulate the inlet of the gas valve manually to control the temperature. According to Ahmad et al., [2], flame produced by wood stove can caused harmful to people. Hence, thermoelectric uses Peltier effect is implemented as an alternative element to a system that produce heat [6-7] and energy source [8].

Nowadays, the dependence on electricity is increasing in household appliances. In food and beverage preparation, heating element is used to replace flame mainly for boil water, toast and cook rice. Recently, the revolution of heating element design and materials are rapidly evolved. One of the latest heating element implementation is using Peltier module. Peltier can describe into two type which is thermoelectric cooling (TEC) and thermoelectric generator (TEG). Both types of this module use the thermoelectric effect. This effect is reversible so that both module types can act as a cooler or a generator. If voltage is applied to a module, it will pump heat, but if a temperature difference is applied across a module a voltage will be produced.

In addition, cooler modules are used for cooling and generator modules are used for generating electricity. This is because the cooler and generator modules have been specifically optimized for different temperature ranges. Cooler modules most effective at temperatures closer to room temperature, as usually found in cooler applications, while generator modules are optimized for higher temperatures [8]. Peltier effect had been implemented in air-conditioning system [9-10], clothes [11-12]. In food and beverage technology, a hot cold tumbler operation was developed by using Peltier effect to remain heat and cold of a $300 \mathrm{cc}$ can of drinks or any liquid [13].

In addition, A PID-based temperature control device for electric kettle was designed to produce heat and best temperature at desired level temperature for different drinks preparation [14]. Commonly, a few of controllers are design to control height, displacement, velocity and rotation angle of a mechanical product [15-16]. Hence, Nair and Mohan [17] using PID controller to control constant temperature according to desired value. Meanwhile, Shah et al., [14] implement PID 
controller to control water temperature for electric kettle. In industry purpose, the PID controller also been used for liquid level control [18] and integrated with LabVIEW for biomedical application [19].

The objective of this research is mainly focused on developing a portable stove for outdoor activities to serve food and beverage easily. The objectives of the research are to design one portable stove using Peltier module and also to design a PID controller to control temperature of the stove. This project focuses on the development of a portable stove that operates by using a Peltier to provide heat. The stove is integrated with Peltier module as a heating element. The minimum operating voltage for the stove is specify to be $10.1 \mathrm{~V}$, and the maximum is $12.6 \mathrm{~V}$, therefore if the supply is lower than the minimum threshold the Peltier will auto shut down. The controller algorithm that is chosen is the Proportional Integral Derivative (PID) controller to control the temperature of heating or cooling when the temperature is being adjusted to its set point. A microcontroller, Arduino Uno R3, will be the main board for operating the program to run the programmers.

There are 2 levels of temperature that is created for this project low and high. LM 35, which is a precision integrated-circuit temperature device, will be utilized to detect the temperature values. Relays will be used to cut off the circuit when the threshold is reach. Components such as heat sink and fan are used for manage the left over heat when the Peltier is close down either suddenly or manually. As for displaying device, a 16×2 Liquid Crystal Display (LCD) will be used to display the current progress. The limitation for this project is to have environmental friendly stove that do not use fuel as a burner but using Peltier to produce heat. Next, this project only focuses on light meals only like the boiling water.

Furthermore, this project can variable desired temperature based on two level temperatures which is low and high. This idea of this project comes to quick set up while environmental friendly when having a camping. This project will encourage people to do not having pollution but use renewable source energy and effectively heating and cooling process like Peltier device. This project will take over a heating process succeed.

\section{Methodology}

The proposed work is the operation of portable stove using Peltier module and temperature programmable stove by using Arduino Uno as shown in Figure 1. Figure 2 shows the process of the system. When the push button $A$ is on, the main system will turn on. The green LED will light up indicating the system is running and the LCD will display message. At the same time, the battery was checked whether the voltage supply is more than $10.1 \mathrm{~V}$ to continue the system. If the voltage is not enough to supply, the system will display the message on LCD and orange led will light up. The system will cut off the Peltier supply.

Then, when push button B is on, it will ready to supply to Peltier. An initial static control signal is output from Arduino result in a OV control voltage on Peltier plate. The system will display again ask to select the desired temperature. If the push button B is turn off which is do not give any supply, so the system will stay and wait until the next response. Customer will select the temperature (L=Low, $\mathrm{H}=\mathrm{High}$ ) desired. If customer chooses low, the display will show the rate of current going to the Peltier and wait for heating the Peltier to reach the desired temperature. It same goes with the other temperature. 


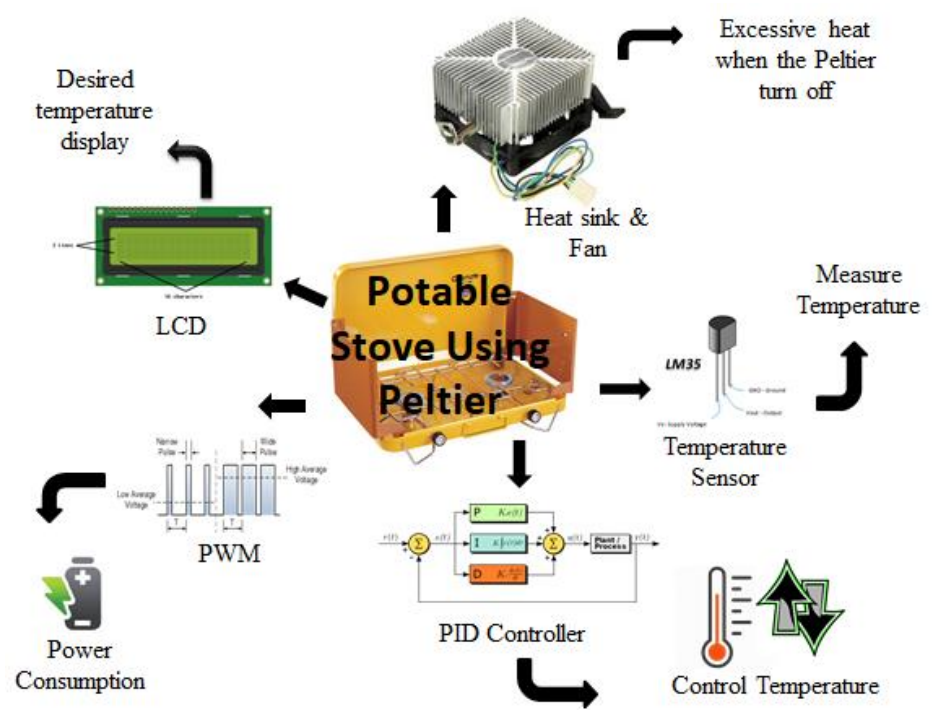

Fig. 1. Project Integration

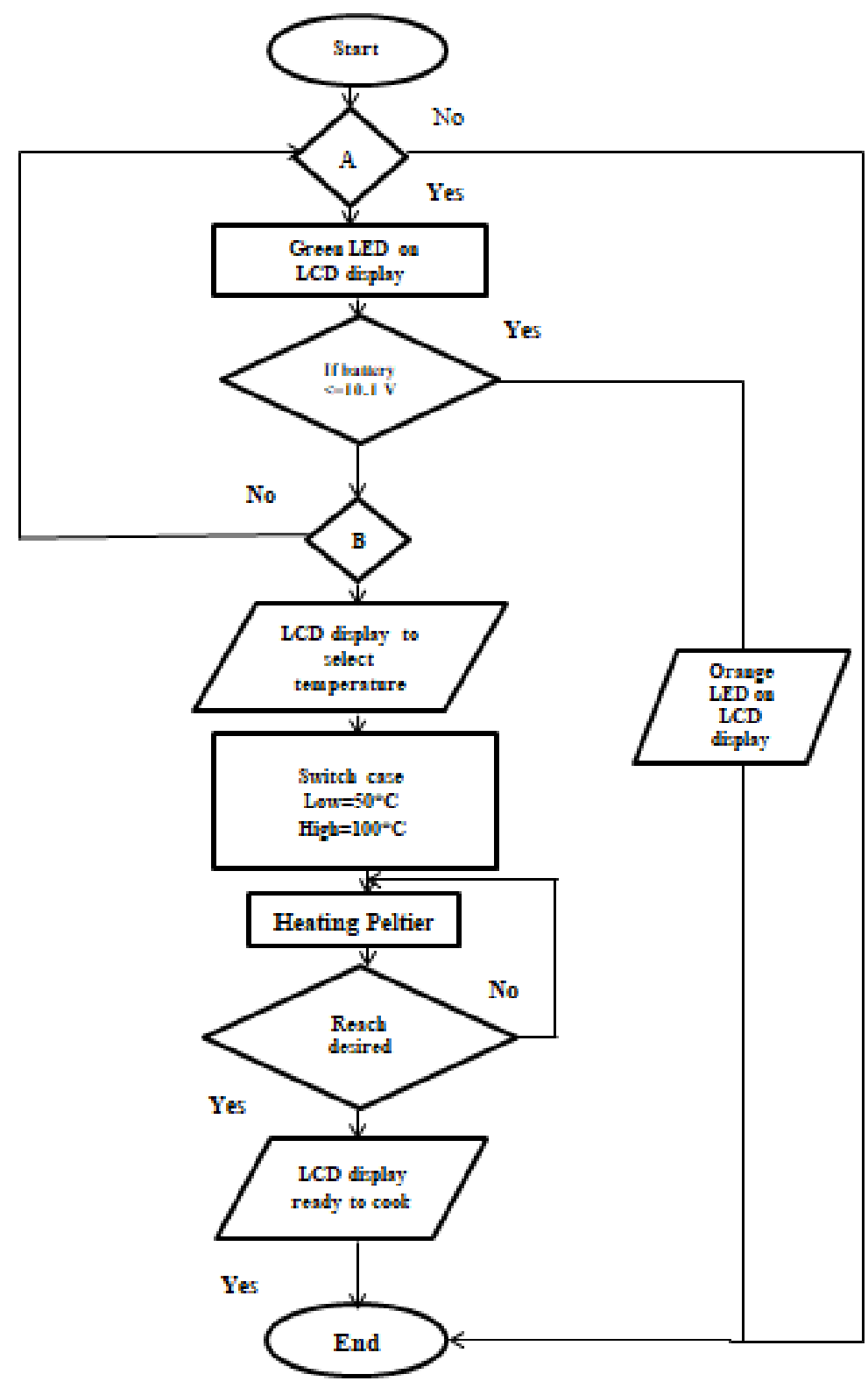

Fig. 2. Flow chart of operating system 
Current temperature is recognized by the temperature sensor unit and passed to Arduino. PID algorithm is running based on the error between current temperature and desired temperature. A dynamic control signal is output to drive the Peltier plate. This step is continually repeated until the desired temperature is equal to current temperature.

The fan wills excessive heat when the Peltier turn off. It is because Peltier cannot stay too long in heat condition. It will make the Peltier worst. Then, if temperature gets at the desired the display will tell customer to get ready to cook. Get the button b to stop the Peltier operation. The current process will stop and back to ready mode. This project will take over a heating process succeed.

\section{Hardware Implementation}

The hardware implementation is an Arduino Uno based system. The hardware implementation of the proposed system is shown in Figure 3 and the developed hardware as shown in Figure 4. The circuit shows Arduino Uno function as a temperature PID controller which aided by a LM35 temperature sensor. The Arduino Uno has 14 digital input output pins for Control Applications. The temperature sensor detects the current temperature of Peltier and converts the signal into corresponding voltage level by a transducer. It is connecting to analogue pin 2 A1 on Arduino board.

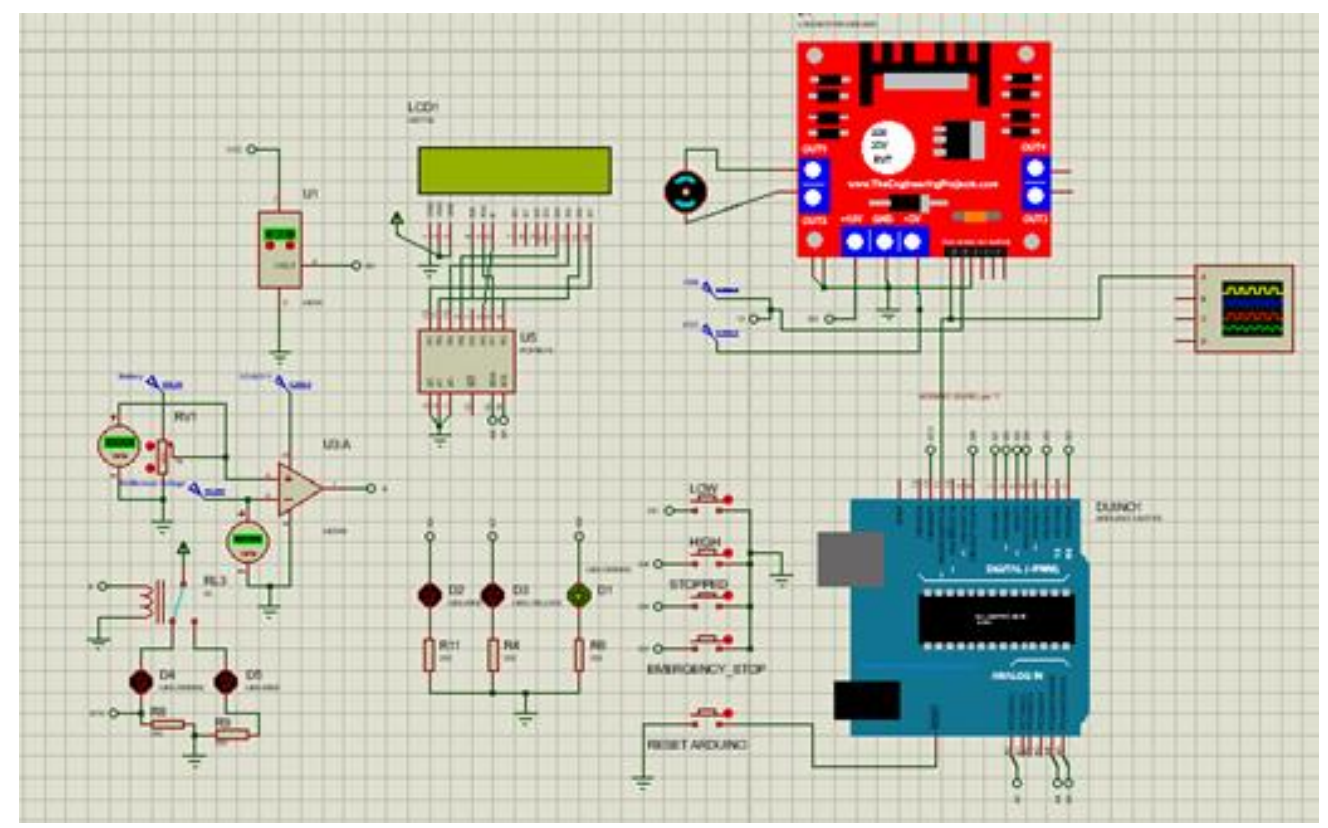

Fig. 3. Circuit design for the whole operation

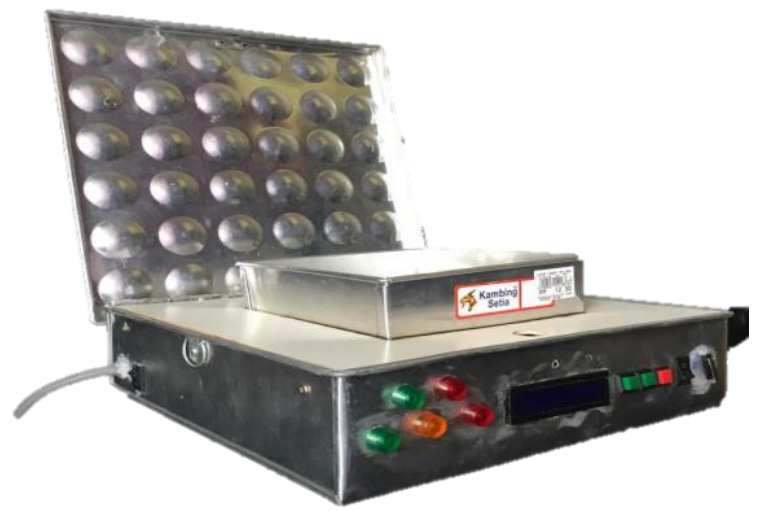

Fig. 4. Prototype of portable stove 
The Arduino circuit is connected with PWM circuit. For this project, one DC motor represents the Peltier. To enhance the motor control system, a motor driver (L298n) was added as the medium to control the Peltier. One motor driver is able to control a pair of Peltier. PWM module allows adjusting and calibrating the supply of Peltier. PWM module provides to control the temperature of Peltier.

For wiring, the motor driver needs external $12 \mathrm{~V}$ power supply. Two output pins form motor driver are connecting directly to the Peltier. To let user have chosen for the desired cooking temperature, a micro key is used which can select in low, medium and high temperature. A comparison between actual and desired temperature will to do and feedback to the microcontroller. The Arduino board will do correction base on the feedback signal by sending a suitable intensity of PWM value to the motor driver. Once the device is overheating, a relay will trigger to active the fan for cooling down the temperature. A heat sink is added to increase the efficiency in cooling process.

Case I: If the current voltage is greater than reference voltage (including tolerance) then controller will reduce the PWM signal, cut off the Peltier supply and turn on the fan.

Case II: If the current voltage is less than the reference voltage (including tolerance), the controller will increase the PWM signal and turn off the fan.

The process of controller will display in the LCD. The current temperature and the set point can be observed on the first line of LCD. And also, the present conditions of the relays are displayed on the second line of the LCD.

\section{Results and Discussion}

As thermo-electric cooler module works in Peltier cooling and heating effect, the system can be implemented in cook stove that can provide tolerable and controlled temperature. A thermoelectric TEC 12706 cooling \& heating system was designed and built which can be used heating a stove. Several Peltier are used to get the heating with a DC power supply through external power supply to get the optimum temperature with the less current uses. It had been shown from testing results that the Peltier is capable of cooling and heating but for this experiment only concerned about the heating process of Peltier as recorded in Table 1. The behaviour of the Peltier heating process is shown in Figure 5.

The test run is divided into two stages which the first stage test is basically test for acquire the best average heating time, temperature and current consumption. The second stage test is tuning the best the PID controller for this system. Then an analysis will do according to the collected data and discuss for the feature. Figure 6 represents the electronic part of stove, it operates the heating operation.

\section{Table 1}

Temperature of hot side of Peltier $\left({ }^{\circ} \mathrm{C}\right)$ vs Time $(\mathrm{s})$

\begin{tabular}{llll}
\hline Time $(\mathrm{s})$ & Hot side $\left({ }^{\circ} \mathrm{C}\right)$ & Time $(\mathrm{s})$ & Hot side $\left({ }^{\circ} \mathrm{C}\right)$ \\
\hline 0 & 29.00 & 100 & 124.1 \\
10 & 39.70 & 110 & 127.5 \\
20 & 53.60 & 120 & 129.4 \\
30 & 67.60 & 130 & 130.5 \\
40 & 73.20 & 140 & 129.9 \\
50 & 77.40 & 150 & 127.5 \\
60 & 86.60 & 160 & 126.5 \\
70 & 93.70 & 170 & 124.8 \\
80 & 102.8 & 180 & 119.0 \\
90 & 111.1 & & \\
\hline
\end{tabular}




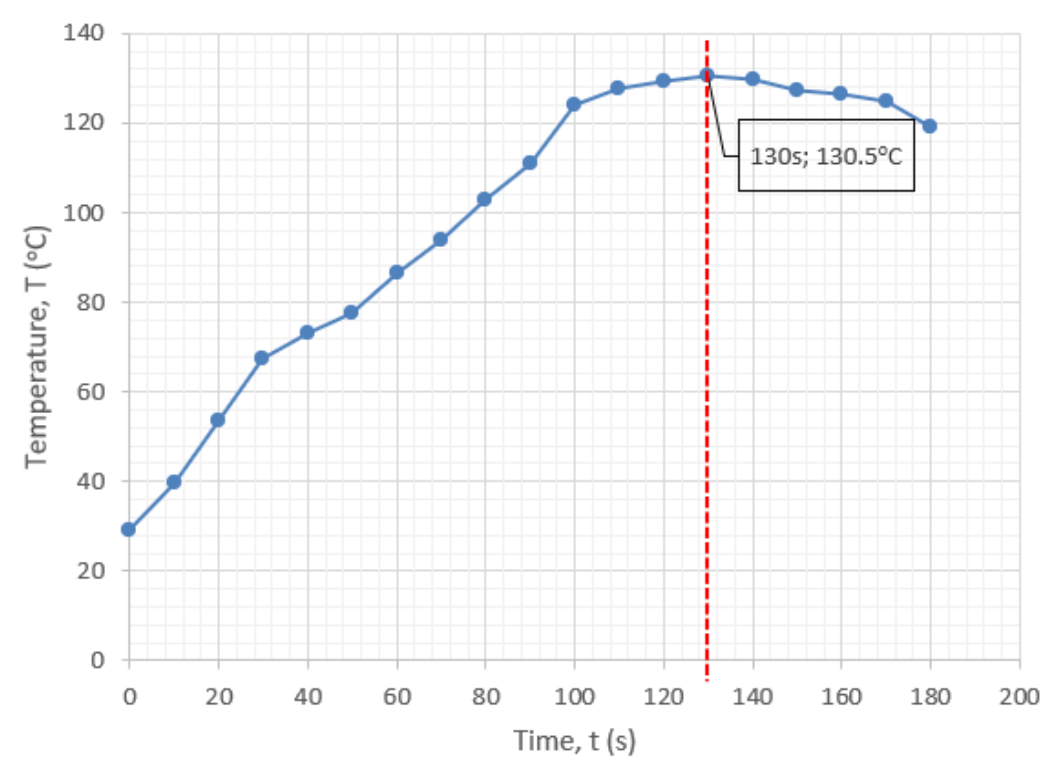

Fig. 5. Peltier temperature behaviour

\subsection{Connection Test}

The connection circuit design for Peltier is parallel because to allow maximum current flow while maintaining the voltage as shown in Figure 6. It is because Peltier device require constant voltage and current. In parallel connection, low voltage and high current are required. It will have just to compensate for heat gain or heat loss from the product. When using a series interconnection, the output current will depend on the smallest current flow of individual cells. An experiment without load was conducted in room temperature condition which is around $29.0^{\circ} \mathrm{C}$. The initial temperature of Peltier is also same as temperature room. The input voltage that had been supply to the system is $12 \mathrm{~V}$. Table 2 listed the current and time taken of peltier without load for temperature $70^{\circ} \mathrm{C}$. The current applied to the without load system for each parallel and series connection are depend on number of the Peltier used as shown in Figure 7.

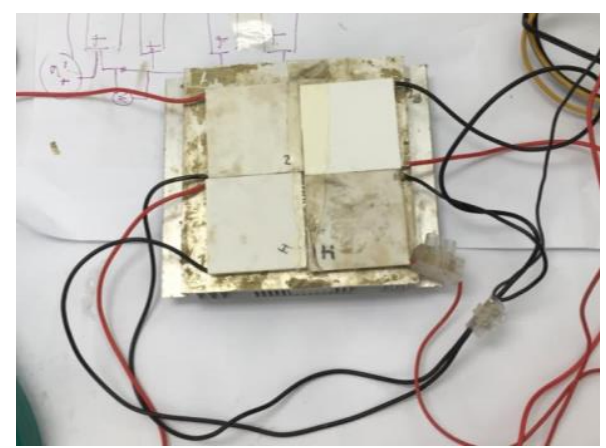

Fig. 6. Connection of 4 Peltier

Table 2

Current and Time Taken of Peltier Without Load for Temperature $70^{\circ} \mathrm{C}$

\begin{tabular}{lllll}
\hline \multirow{2}{*}{ No of Peltier } & \multicolumn{2}{l}{ Current, I (A) } & Time, $t(\mathrm{sec})$ \\
& Series & Parallel & Series & Parallel \\
\hline 2 & 1.00 & 3.78 & 89 & 18 \\
3 & 0.71 & 5.10 & 750 & 34 \\
4 & 0.57 & 6.30 & 813 & 37 \\
\hline
\end{tabular}




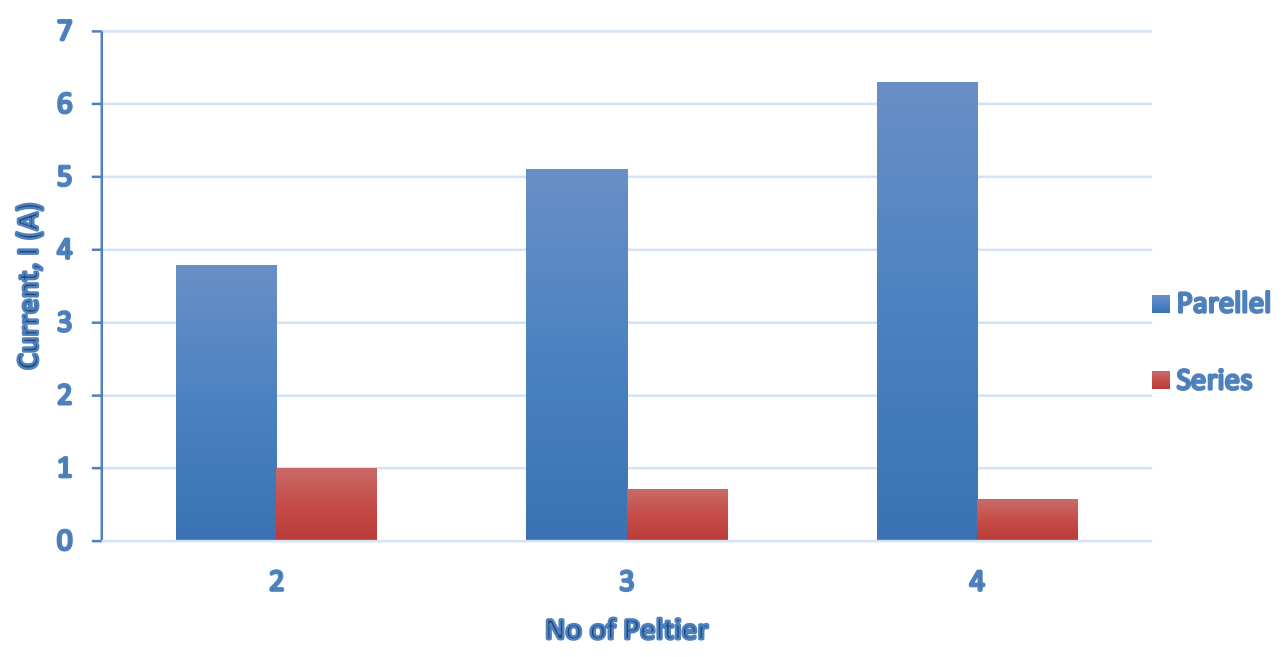

Fig. 7. Parallel and series connection of Peltier without load

An experiment with load was conducted by adding a pot with load $250 \mathrm{~m} \ell$ of water as shown in Figure 8. It can conclude that the time taken for one Peltier to heating with the present of load as recorded in Table 3. The more time taken is needed to heating the water until $70^{\circ} \mathrm{C}$ because the heats transfer from the warmer part to the cooler part which is the pot by convection. The heat was transfer through the fluid by the pot of heating water. The temperature tested is decided at $70^{\circ}$ to avoid the Peltier reach its breakdown point if the test is overlooked. Figure 9 show the parallel and series connection of peltier with load.

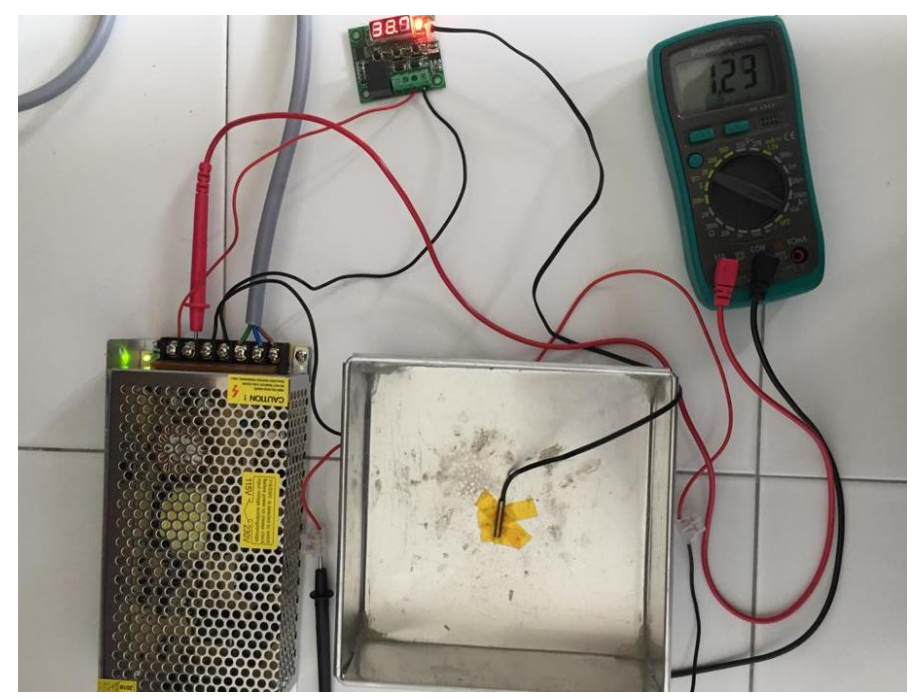

Fig. 8. Heating testing using $250 \mathrm{ml}$ of water

\section{Table 3}

Current and Time Taken of Peltier With Load of $250 \mathrm{ml}$ for Temperature $70^{\circ} \mathrm{C}$

\begin{tabular}{lllll}
\hline \multirow{2}{*}{ No of Peltier } & \multicolumn{2}{l}{ Current, I (A) } & Time, $\mathrm{t}(\mathrm{sec})$ & \\
& Series & Parallel & Series & Parallel \\
\hline 2 & 1.00 & 3.78 & 89 & 18 \\
3 & 0.71 & 5.10 & 750 & 34 \\
4 & 0.57 & 6.30 & 813 & 37 \\
\hline
\end{tabular}




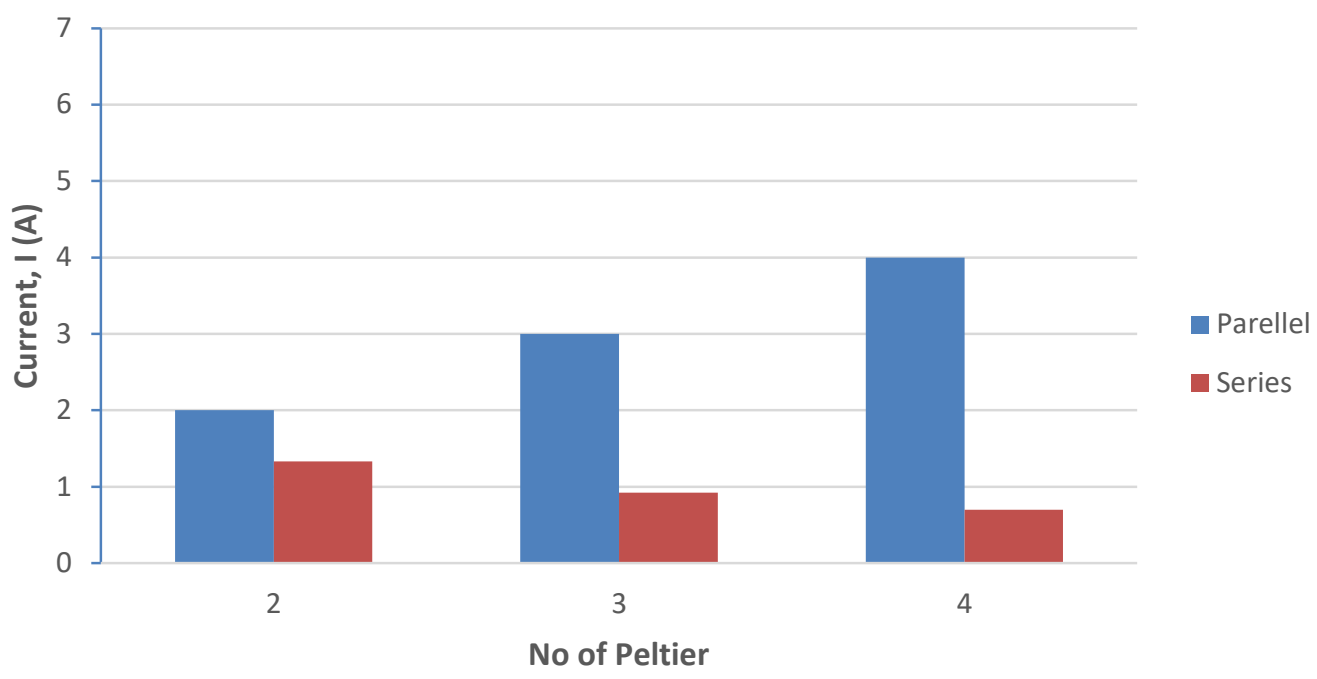

Fig. 9. Parallel and series connection of Peltier with load

This experiment was conducted to measure and to know the behaviours of the temperature for the Peltier system in open loop. Without PID control to maintain and minimizing the error, the temperature will fluctuate until the maximum temperature that the Peltier can reach. No set point will set to maintain the temperature. So, the temperature is increase extremely by time. The system is unstable due to high gain. Figure 8 shows the temperature versus time of Peltier without using PID controller in 70 seconds.

\subsection{Temperature Control}

\subsubsection{PID controller parameter tuning}

This experiment was conducted to measure and to know the behaviours of the temperature for the Peltier system in open. Without PID control to maintain and minimizing the error, the temperature will increase extremely until the system reach the breakdown point of the Peltier. fluctuate until the maximum temperature that the Peltier can reach. Desired temperature point will set to maintain the temperature as shown in Figure 10. So, the temperature is increase extremely by time loop as shown in Figure 5.

The PID controller is designed by using manual tuning method. By using manual tuning method, the PID controller parameter is determined by increasing the proportional $\left(k_{p}\right)$ parameter while the integral $\left(k_{i}\right)$ and derivative $\left(k_{d}\right)$ parameters are set to zero value. The proportional gain $\left(k_{p}\right)$ is increased until it reaches the set point temperature, at which the output of the loop starts to oscillate. Then, the $K_{i}$ parameter is tuned or increased until bring to the set point with the number of oscillations desired. Finally, $\mathrm{K}_{d}$ parameter is tuned until the output oscillation saturate to the desired temperature and reduced the steady-state error of the output.

Figure 11 shows the influence of PID controller in controlling the temperature at two level which are low level at $50^{\circ} \mathrm{C}$ and high level at $100^{\circ} \mathrm{C}$. The proportion parameter $\left(\mathrm{K}_{\mathrm{p}}\right)$ is increased to 90 with the Integral gain $\left(\mathrm{K}_{\mathrm{i}}\right)$ is increased to 30 and Derivative gain $\left(\mathrm{K}_{\mathrm{d}}\right)$ is increased to 80 . At the first manual tuning, $\mathrm{Kp}$ is set to 10 while $\mathrm{Ki}$ and $\mathrm{Kd}$ constant zero to find the minor overshoot to allow the temperature set point to be reached. To determined PID value manually, it is best to begin varying only proportional term with the integral and the derivative equal to zero. This method is starting with the small value for the proportional term until the temperature become unstable. Each case begins with a set point of $37^{\circ} \mathrm{C}$. 


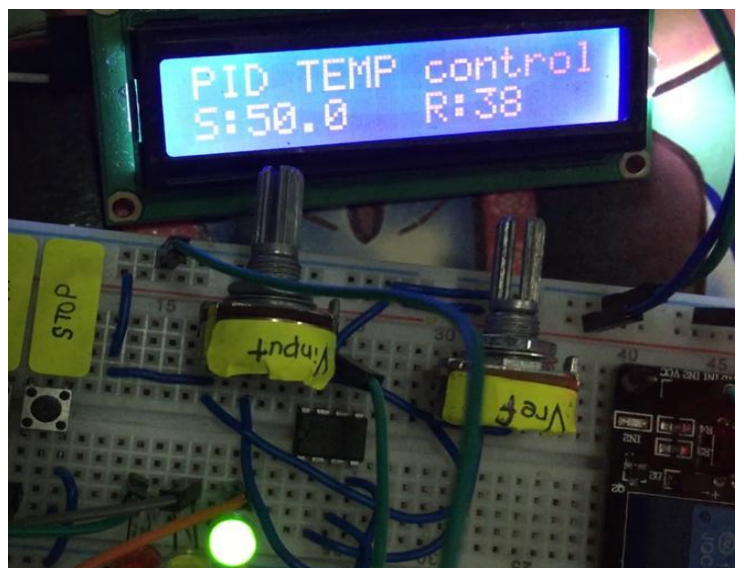

Fig. 10. LCD display of heating stove equipment

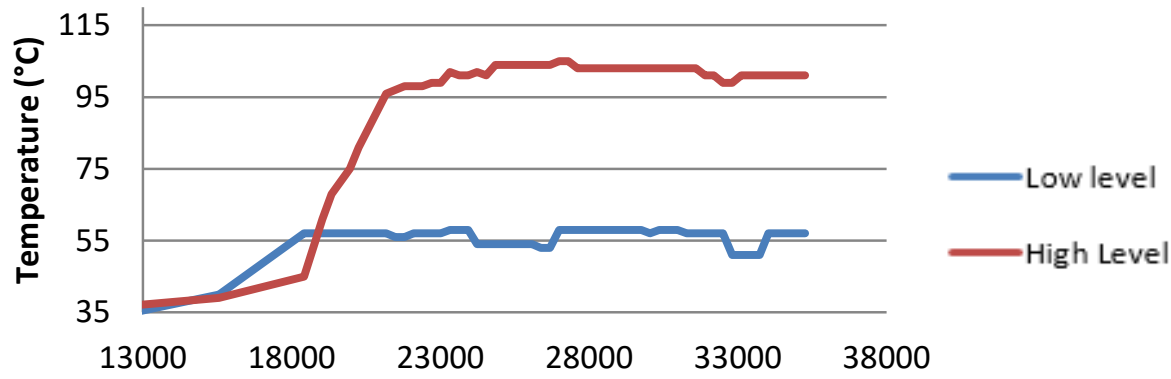

Time (S)

(a)

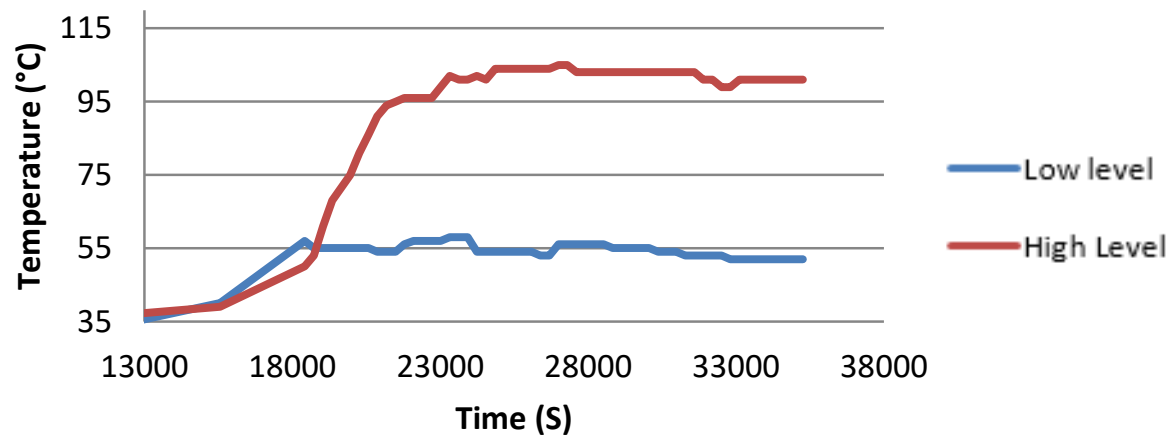

(b)

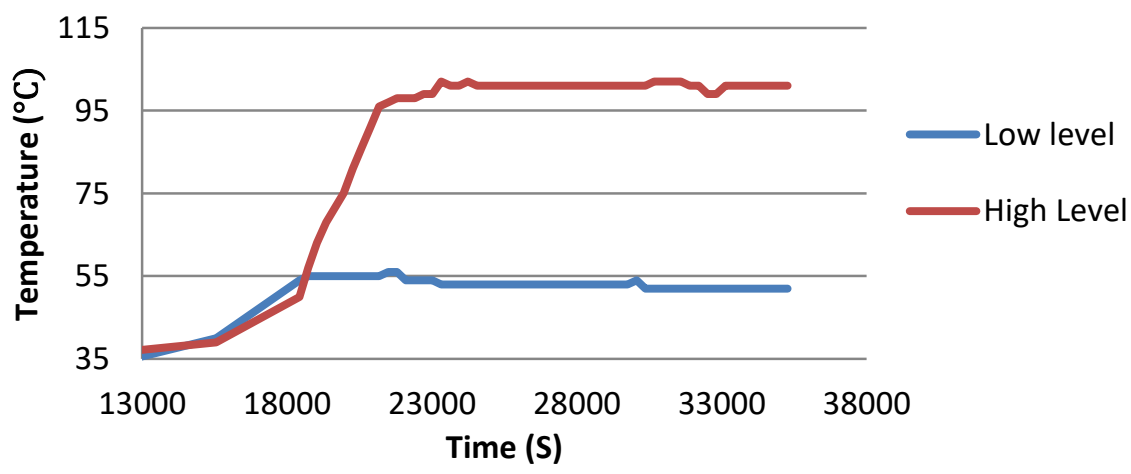

(c)

Fig. 11. Tuning PID Controller (a) $K_{P}=20, K_{I}=10, K_{D}=10$; (b) $K_{P}=50, K_{I}=35$, $K_{D}=60 ;(c) K_{P}=90, K_{I}=30, K_{D}=80$ 


\section{Conclusions}

As a conclusion, portable stove was designed and implemented an efficient temperature monitoring and controlling system with an Arduino board. A PID Manual Tuning Method was used for control the heating process. The PID parameter, $K_{P}=90, K_{I}=30, K_{D}=80$ show the best parameter for heating control process based on the minimization of temperature error versus the process set point. The temperature is more stable with less fluctuation behaviour to reach the desired temperature given. Therefore, the implementation PID controller in controlling temperature is proven.

\section{Acknowledgement}

This work has been supported by the Department of Electrical Engineering Technology and the authors would like to express appreciation to Universiti Teknikal Malaysia Melaka.

\section{References}

[1] Outdoor Foundation. "Outdoor Participation Report." 2016.

[2] Ahmad, M., S. S. Hussain, and S. A. Malik. "Burns from a stove burst: analysis of 34 cases." Annals of burns and fire disasters 20, no. 4 (2007): 173.

[3] New Hampshire Department of Environmental Services. "NHDES Fact Sheet: Wood Stoves and Air Pollution." 2019.

[4] Igboanugo, A. C., and M. U. Ajieh. "Design and construction of a biomass stove for cooking in rural settlements in Nigeria." Nigerian Research Journal of Engineering and Environmental Sciences 2, no. 2 (2017): 351-359.

[5] K. Knapp. "How to Choose the Right Backpacking Stove Fuel." REI Co-op Journal, 2018.

[6] Alaoui, Chakib. "Peltier thermoelectric modules modeling and evaluation." International Journal of Engineering (IJE) 5, no. 1 (2011): 114.

[7] He, Wei, Gan Zhang, Xingxing Zhang, Jie Ji, Guiqiang Li, and Xudong Zhao. "Recent development and application of thermoelectric generator and cooler." Applied Energy 143 (2015): 1-25. https://doi.org/10.1016/j.apenergy.2014.12.075

[8] Hájovský, Radovan, Martin Pieš, and Lukáš Richtár. "Analysis of the appropriateness of the use of peltier cells as energy sources." Sensors 16, no. 6 (2016): 760. https://doi.org/10.3390/s16060760

[9] Shafiei, Nuraini, Mohamad Haniff Harun, K. A. M. Annuar, M. F. A. Halim, M. S. M. Aras, and A. H. Azahar. "Development of Portable Air Conditioning System Using Peltier and Seebeck Effect." Journal of Telecommunication, Electronic and Computer Engineering (JTEC) 8, no. 7 (2016): 97-100.

[10] Totala, N. B., V. P. Desai, Rahul KN Singh, Debarshi Gangopadhyay, Mohd Salman Mohd Yaqub, and Nikhil Sharad Jane. "Study and fabrication of thermoelectric air cooling and heating system." Int J Eng Invent 4 (2014): 20-30.

[11] Lavanya, G., S. Venkanteshwarlu, A. Nagaraju, and G. Prasanthi. "Cooling and Heating of Refrigerator Jacket by Using Peltier Effect." Insight Mechanical Engineering 1, no. 1 (2016).

[12] Ahammed, KM Nizar. "Thermoelectric Cooling Prototype Jacket." MES J. Technol. Manage 5 (2013): 85-94.

[13] Lee, Robin, Chong Chee Kiong, Chin Tin Huang, and Ratnakar Kulkarni. "Development and Testing of Hot Cold Tumbler Operating on Peltier Effect." International Journal Of Engineering Technology And Sciences (IJETS) 7, no. 1 (2017): 1-5.

[14] Shah, Mohd Badril Nor, Norfahaniza Zailany, Amar Faiz Zainal Abidin, Mohd Firdaus Halim, Khalil Azha Annuar, Arman Hadi Azahar, Muhamad Haniff Harun, and Muhammad Faizal Yaakub. "PID-based temperature control device for electric kettle." International Journal of Electrical and Computer Engineering 9, no. 3 (2019): 1683. https://doi.org/10.11591/ijece.v9i3.pp1683-1693

[15] Mohd Annuar, Khalil Azha, Md Zin, Muhammad Haikal, Mohamad Haniff Harun, Mohd Ab Halim, Mohd Firdaus, and Arman Hadi Azahar. "Design and development of search and rescue robot." International Journal of Mechanical \& Mechatronics Engineering (2016): 36-41.

[16] Azahar, Arman Hadi, Chong Shin Horng, and Anuar Mohamed Kassim. "Vertical motion control of a one legged hopping robot by using central pattern generator (CPG)." In 2013 IEEE Symposium on Industrial Electronics \& Applications, pp. 7-12. IEEE, 2013. https://doi.org/10.1109/ISIEA.2013.6738958

[17] Nair, Radhika, and K. R. Mohan. "Control of Temperature Using PID Controller." International Journal of Science and Research (IJSR) 5, no. 5 (2015): 1203-1206. https://doi.org/10.21275/v5i5.NOV163686 
[18] K. A. M. Annuar, N. A. A. Hadi, I. M. Saadon, and M. H. Harun. "Design and Construction of Liquid Level Measurement System." Journal of Advanced Research in Applied Mechanics 12, no. 1 (2015): 8-15.

[19] N. H. Ariffin and N. Arsad. "Design of PID Control System Assisted using LabVIEW in Biomedical Application." Journal of Advanced Research in Applied Mechanics 15, no. 1 (2015): 1-9. 